\title{
EDITORIAL
}

\section{Génesis de una revista médica}

\section{Genesis of a medical journal / Gênese de uma revista médica}

Mario Melguizo Bermúdez ${ }^{1}$

La manifestación escrita de lo académico, de lo científico, de lo artístico y de las cosas comunes ha sido una necesidad inherente al hombre... y ha sido una continuación de esa necesidad de hablar que el hombre tuvo cuando empezó a comunicarse con los demás. Darwin decía que el lenguaje nació cuando el hombre trató inconscientemente de imitar con las cuerdas vocales los gestos involuntarios de las manos ${ }^{1}$.

El lenguaje, tanto oral como escrito, ha surgido como una necesidad del hombre. Cervantes decía que "la pluma es lengua del alma; cuales fuesen los conceptos que en ella se engendrasen tales serán sus escritos" 1 .

Escribir ha sido, pues, un sueño del hombre que le imprime rasgos casi divinos. Con la palabra escrita se pueden brindar las más grandes de las alabanzas y, al mismo tiempo, podemos sumergirnos en las reconditeces absurdas de las más bajas pasiones humanas.

En su origen, la escritura era una especie de magia y conservó durante mucho tiempo este carácter. Las primeras líneas escritas en las que figuraba el nombre de una persona eran encantamientos, fórmulas de propiciación o de curación, de abovedamiento o maleficio. Si la palabra pronunciada puede tener una virtud mágica, con mayor razón la tendrá la palabra escrita. Los primeros escritores fueron, pues, los hechiceros. Cuando la palabra escrita se despojó de todo carácter mágico, quedó rodeada de un halo de temor y respeto ${ }^{2}$.

Sin embargo, las primeras representaciones de palabras parecen haber sido signos mnémicos, como nudos, marcas en palos, etc. Los quipus de los incas alcanzaron un alto grado de perfección ${ }^{1}$. Posteriormente, de estos signos mnémicos, se pasó a los dibujos en las cuevas, lo que daría lugar a los ideogramas. Los antiguos sumerios fueron, probablemente, los primeros en pasar del dibujo a la escritura hace más de 5000 años ${ }^{1}$.

Se calcula que hay en el mundo cerca de tres mil lenguajes diferentes. Antes del Renacimiento, la medicina hablaba un lenguaje común: a las lenguas semíticas primitivas sucedió el griego clásico, que a su vez fue reemplazado por el latín y más tarde por el árabe durante casi toda la Edad Media. Esta sucesión de lenguas ha dejado términos que actualmente se utilizan y cuyo origen, como veremos, es a veces bastardo, pero poco a poco han logrado legitimidad. Veamos un solo ejemplo: los términos "cefálico" y "basílico", que se aplican a las venas del brazo, provienen de los términos kifal y basilik, que significan interno y externo y son producto de la ignorancia del árabe por parte de algunos traductores primitivos. "nuez de Adán”y “duramadre” son traducciones literarias de nombres árabes imaginativos ${ }^{1}$.

Al leer nuestra literatura médica encontramos palabras -que si estudiamos en sus orígenes- provienen de todo el mundo: chaulmogra (árbol cuyas semillas suministran un aceite empleado en la lepra y en otras afecciones cutáneas) es birmano; kaolin, chino; cáscara sagrada, español; moxa, japonés. Y qué decir de las que agregamos nosotros de este lado del mundo, tras el descubrimiento de América: guaiacum e ipeca, guaraníes; curare (worara), peruano; coca, de los Andes, etc... En fin, la forma escrita de las palabras es una necesidad social y esta, la sociedad, ha ejercido una presión para volverla práctica y perfeccionarla.
Forma de citar este artículo: Melguizo M. Génesis de una revista médica. Med UPB. 2019;38(1):7-10. DOI:10.18566/medupb.v38n1.a01

1. Editor emérito de Medicina UPB. Universidad Pontificia Bolivariana, Medellín, Colombia.

Dirección de correspondencia: Mario Melguizo Bermúdez. Correo electrónico: mariomelguizo@gmail.com 
La palabra escrita es tan maleable y polifacética que permite estos malabares imaginados por Octavio Paz:

Lo más fácil es quebrar una palabra en dos. A veces los fragmentos siguen viviendo, con vida frenética, feroz, monosilábica. Es delicioso echar ese puñado de recién nacidos al circo: saltan, danzan, botan y rebotan, gritan incansablemente, levantando sus coloridos estandartes... A la palabra torre le abro un agujero rojo en la frente. A la palabra odio la alimento con basuras durante años, hasta que estalla en una hermosa explosión purulenta que infecta por un siglo el lenguaje. Mato del hambre al amor, para que devore lo que encuentre. A la hermosura le sale una joroba en la U. Y la palabra talón, al fin en libertad, aplasta cabezas con una alegría regular, mecánica. Lleno de arena la boca de las exclamaciones... ${ }^{3}$.

Con las palabras podemos jugar, hacerlas sonar, escribir en serio y trasmitir nuestros sentimientos.

Hecho este recorrido obligado por las posibilidades del lenguaje, y reconociendo que sin él no existirían los medios escritos, entre ellos las revistas médicas, los invito a retroceder en el tiempo y a recordar.

Definitivamente el tiempo pasa, pero deja tras sí una serie de realizaciones. Hablar de la revista Medicina $U P B$ me produce un poco de rubor porque siento como si estuviera hablando de mí mismo. Y pese al rubor que me produce -y lo digo así a destajo y con desparpajoprosigo en mi discurso, porque sé que me le he entregado con amor y dedicación durante todos estos años. Y no solo a ella, sino también a las otras actividades encomendadas por la Escuela en la Coordinación de Cirugía, como Jefe de la Oficina de Postgrados y como primer Jefe de Formación Avanzada de la Universidad. Pero la revista de medicina ha sido mi bien amada; y es que uno se enamora y es por ello que cuando iba a presentar alguna conferencia en algún ambiente académico y se me preguntaba, para efectos de presentación, siempre contestaba: "diga que soy un cirujano y el editor de la revista Medicina UPB, que es el título que más me gusta”.

¿Cómo nació Medicina UPB? Debemos situarnos en el año de 1981, entrado el mes de marzo, sentados en la oficina de postgrados el doctor Alberto Robledo Clavijo y yo. La Facultad de Medicina apenas estaba conduciendo su primera cosecha y me había correspondido diseñar en aquel entonces el currículo de Cirugía del último semestre de medicina, para lo cual había suspendido todas las actividades propias de mi oficio de cirujano y me había dedicado a escribirlo con dedicación exclusiva. No se habían graduado aún los primeros egresados. Era esa época de lucha sin cuartel, donde nacer, para una nueva facultad de medicina, había sido casi una herejía y crecer, una blasfemia. Existía solo una facultad de medicina en la ciudad, que de alguna manera veía lesionados sus intereses, pues dejaba de ser la única y obligaba a ambas a ser la mejor, a competir sanamente. Luego vino el CES (Centro de Estudios de la Salud), que se constituyó en una nueva competencia para las dos anteriores. Cada una debía ser la mejor y graduar médicos lindando con la excelencia. Era pues un ambiente académico y propicio para la creación y desarrollo de las nuevas facultades de medicina.

En ese ambiente nos movíamos y luchábamos por la Facultad de Medicina que, repito, produciría en pocos meses su primera cosecha. Y junto con el profesorado de aquel entonces, nos sentíamos orgullosos de nuestros discípulos que pronto saldrían a mostrar a la comunidad que su ejercicio estaba guiado por la ética, el trabajo y el estudio, enraizados en profundos principios católicos. Este ambiente de academia y de realizaciones, junto con la vasta experiencia del doctor Robledo y -de parte mía-, la juventud de aquel entonces y unos deseos inmensos de participar activamente en una revista médica, fueron terreno abonado para que el primero propusiera su creación.

Secundé la idea sin vacilar y juntos trabajamos en el primer número de dicha revista que se llamaría Medicina UPB. El doctor Robledo había dirigido durante muchos años la revista Antioquia Médica, de la Facultad de Medicina de la Universidad de Antioquia, la cual llegó a ser conocida allende las fronteras patrias por su excelente calidad. Yo solo aportaría mi interés por las cosas del lenguaje y varios años de experiencia como corrector de pruebas en un periódico estudiantil. Era época de sueños, pero bastante salpicados de realidad. Sabía que mi aporte era pequeño, pero mis deseos de hacer las cosas bien eran grandes. Se constituyó el Consejo de Redacción conformado por el bioquímico Guillermo Acebedo Acebedo y los médicos Oscar Duque Hernández, Ramón Córdoba Palacio, Iván Molina Vélez, el estudiante de medicina Jorge Madrid Vélez y yo. Como editor el doctor Alberto Robledo Clavijo. Con la colaboración de la Universidad y sus facultades correspondientes, se estudió y diseñó la carátula. De aquí en adelante, hasta la fecha, se ha venido publicando de manera ininterrumpida. Desde el segundo número recibí la opción de ser su editor y el doctor Robledo pasó a conformar el Consejo de Redacción.

La revista se presentó ante la comunidad médica, que la recibió con escepticismo y nadie confiaba en que su existencia se prolongaría más allá de uno o dos años. ¡Y llevamos 38! Sin embargo, se enseñoreó en el ambiente y llegó a constituirse en la única del medio, pues Antioquia Médica entró en crisis. Los profesores de las tres facultades de medicina existentes empezaron a publicar sus trabajos en nuestra revista y durante unos tres años 
fue el único medio de publicación médica en Antioquia. Aparecieron posteriormente las revistas Medicina CES, Iatreia, de la Facultad de Medicina de la Universidad de Antioquia y Anales de la Academia, de la Academia de Medicina de Medellín, institución fundada en esta ciudad en 1887.

Se consiguió el ISSN (Internacional Standard Serial Number) y ya, con su cédula de ciudadanía, empezamos a enviarla a las facultades de medicina de nuestro país y del exterior. Fue así como la solicitud de canje fue creciendo y con el tiempo la hemeroteca llenó sus anaqueles con adquisiciones por intercambio.

Poco a poco Medicina UPB se abrió campo en los ambientes universitarios y académicos, y para 1985 la Biblioteca Regional de Medicina (Bireme), con sede en Brasil,la incluyó en su Index Medicus Latinoamericano. De otro lado, el Centro de Información y Documentación Científica, CIDOC, de la Universidad de Rosario, Argentina, la incluyó en Contenidos Corrientes Latinoamericanos: Ciencias de la Salud. Posteriormente fue incluida en el Programa SIBRA de la Federación Panamericana de Facultades de Medicina (FEPAFEM). Nuestra revista alimentaba la Base Nacional de Datos y el Programa Nacional de Analíticas del ICFES.

En un estudio de tipo técnico realizado en 1988, Medicina UPB fue la mejor calificada entre $47 \mathrm{pu}^{-}$ blicaciones periódicas de nuestra Universidad. Dicho estudio analizó en detalle las normas del ICONTEC $\mathrm{y}$ su aplicación en esas publicaciones.

Paulatinamente Medicina UPB fue adquiriendo su propia personalidad y ahora es una adulta muy bien definida. Su primer artículo era de corte humanístico y el resto era el fruto del esfuerzo de profesores, internos residentes y estudiantes, quienes volcaban en ella los resultados de sus investigaciones y estudios. El Caso de infecciosas -que siempre estaba presente- fue responsabilidad de la Corporación de Investigaciones Biológicas -CIB- y particularmente de la infatigable colaboración de la doctora Ángela Restrepo Moreno. Hacía también parte de su personalidad la sección Excerpta, donde publicábamos los resúmenes de las muy interesantes investigaciones efectuadas por los estudiantes de Medicina de la comunidad y que antes de que surgiera la idea de publicarlos estaban condenadas a dormir en fríos e inconsultos anaqueles de la biblioteca. Y de verdad que eran acogidos y con frecuencia nos eran solicitados los trabajos completos. Desde 1988 se introdujo, como importante novedad, la sección Arte Médico, con el fin de estimular el interés por el arte y otras disciplinas en los estudiantes de medicina y la comunidad médica en general y, a su vez, fue útil para identificar cada nuevo número de la revista, al ser publicado en la portada.

Sosteníamos canje, para 1991, con 125 títulos de revistas en todo el mundo, lo que representaba el $35 \%$ de todos los títulos (358) que adquiría la biblioteca médica en ese entonces. Los países con los cuales sosteníamos canje eran: Argentina, Brasil, Colombia, Corea, Cuba, Chile, Ecuador, España, Estados Unidos, Francia, Guatemala, Italia, Japón, México, Pakistán, Panamá, Puerto Rico, República Dominicana, Suiza, Portugal, Uruguay y Venezuela.

En sus comienzos, la revista fue editada por fuera de la Universidad, pero nuestra editorial asumió el proceso de edición y actualmente la edita en su totalidad. Pero también la revista Medicina UPB se vio en ocasiones envuelta en mares de dificultades, con olas de tal altura que, para noviembre de 2001, no había podido ser editado el número uno y único del volumen 20 de ese año. ¡Así, críticamente, celebramos nuestro vigésimo aniversario!

Pero nos propusimos mejorar día a día y continuar con la ardua labor que significaba mantenernos como una revista líder en Antioquia, que además llegaba a los cinco continentes y que, al contrario de otras, se había mantenido sin interrupción y con los más altos estándares de competencia por la pulcritud en el respeto a las normas internacionales y la calidad de los artículos.

La necesidad del consueta la suplí con mi esposa y mis hijos, quienes pacientemente me leían los originales para poder confrontarlos con los textos levantados en la editorial. Era un trabajo nocturno o de fines de semana que me consumía varias horas diarias cuando estábamos en proceso de publicación. Por eso digo yo que no siempre los sueños son y, parodiando a Rubén Darío con su corto pero bellísimo cuento El velo de la reina Mab, cuando discutíamos en aquel lejano 1981 sobre nuestras aspiraciones y dificultades en torno a nuestra revista:

La reina Mab en su carro hecho de una sola perla, tirado por cuatro coleópteros de petos dorados y alas de pedrería, caminando sobre un rayo de sol, se coló un día por la ventana de una buhardilla, donde estábamos dos hombres pensativos, tristes e impertinentes, lamentándonos de lo que aún no habíamos logrado realizar. Entonces, la reina Mab, del fondo de su carro, hecho de una sola perla, tomó un velo azul, casi impalpable, como formado de suspiros o miradas de ángeles rubios y pensativos. $Y$ aquel velo era el velo de los sueños, de los dulces sueños que hacen ver la vida color de rosa. $Y$ con él nos envolvió. Y dejamos de estar tristes, porque nos penetró la esperanza y en nuestras cabezas el sol alegre, con el diablillo de la vanidad que consuela en sus profundas decepciones a los pobres artistas.

¡Y se convirtió en realidad ese sueño! ¡Y ahora, también a mí me consuela el diablillo de la vanidad!

¡Señores, no siempre los sueños, sueños son! 
Me sucedió en la dirección de la revista el investigador Jorge Donado, quien con el apoyo de sus colaboradores consiguió que fuera indexada en la Categoría $\mathrm{C}$ del Índice Bibliográfico Nacional Publindex. Actualmente, el siquiatra José Gabriel Franco Vásquez, quien seguramente logrará situarla en lugares más altos en los ambientes académicos, se ha encargado de su dirección.
Al doctor Franco le digo, con Víctor Frankl -seguramente su amigo- que: "mediante la entrega a la misión que la comunidad le impone, en la que se ve metido o ante la cual se encuentra ya al nacer, el hombre gana en vez de perder y gana concretamente, una suma de responsabilidad adicional"4.

\section{REFERENCIAS}

1. Palabras y Ciencia. MD en Español 1962; 1: 35-41

2. Vendryes J. La lengua escrita y la ortografía. En: El lenguaje. Barcelona: Ed. Cervantes; 1925. p. 447-463

3. Paz O. ¿Águila o sol? (sexta reimpresión 1987). México: Fondo de Cultura Económica; 1987

4. Frankl, Viktor. Psicoanálisis y existencialismo. $2^{\mathrm{a}}$ ed. en español de la $8^{\mathrm{a}}$ en alemán. México: Lito Ediciones Olimpia S.A.; 1978. 